boundary conditions, atmospheric forcing, and ice model have been changed. In particular, a much more robust wind forcing was obtained by replacing the monthly mean wind fields with a 30-year means in order to obtain a seasonal forcing closer to climatology. With regard to the ice rheology, a cavitating fluid model in spherical coordinates which fully conserves ice mass and air sea heat exchanges was employed. The idea here is to attenuate less of the stress into the ocean so that even though the circulation is somewhat sluggish due to large viscous damping, a reasonable current field for the Arctic Basin might be obtained.
Two types of prognostic circulation experiments were carried out with this model using different southern boundary conditions. In one case, a diagnostic relaxation near the boundary as used by Hibler and Bryan (1987) was employed. In this case, heat mass and salt transports through the southern boundary are essentially simulated. In the second case, the net burotropic flow through the FaeroShetland passage and Denmark Strait were specified with the baroclinic transports partially specified by diagnostic relaxation terms. The results from both these models are analyzed with special attention to the ice edge location and the character of the baroclinic fields in the Arctic Basin.

\title{
ON THE INTERANNUAL VARIABILITY OF A DIAGNOSTIC ICE-OCEAN MODEL \\ (Abstract)
}

by

W.D. Hibler, III and Peter Ranelli

(Thayer School of Engineering, Dartmouth College, Hanover, NH 03755, U.S.A.)

Sea-ice drift and dynamics can significantly affect the exchanges of heat between the atmosphere and ocean and salt fluxes into the ocean. The ice drift and dynamics, in turn, can be modified by the ocean circulation. This is especially true of the ice margin location whose seasonal characteristics are largely controlled by the substantial oceanic heat flux in the Greenland Sea due to convective overturning.

A useful framework to analyze the interannual variability of ice-ocean interaction effects relevant to climatic change is the diagnostic ice-ocean model developed by Hibler and Bryan (1987). In this model, the oceanic temperature and salinity is weakly relaxed (except in the upper layer of the ocean which is essentially driven by the ice dynamic-thermodynamic sea-ice model) to climatological temperature and salinity data. This procedure allows seasonal and interannual variability to be simulated while still preventing the baroclinic characteristics of the ocean circulation from gradually drifting off into a total model defined state. However, in the work of Hibler and Bryan only the seasonal equilibrium characteristics of this model with the same forcing repeated year after year have been considered.
In order to begin to examine the interannual behavior of this model, we have carried out a three-year simulation for the Arctic Greenland and Norwegian seas over the time period 1981-83. (The geographical region is essentially the same as used by Hibler and Bryan.) This three year simulation is carried out after an initial two year spin up using the 1981 atmospheric forcing data. For comparison purposes, an ice model simulation with only a fixed depth mixed layer was also carried out over this time interval.

The results of these two simulations are analyzed with special attention to the ice margin characteristics in the Greenland and Norwegian seas to determine the role of ocean circulation on the variability there. The ice margin results are also compared to the variability in the northward transports of heat through the Faero-Shetland passage which in the fully-coupled model are calculated rather than specified.

\section{REFERENCE}

Hibler, W.D. III and K. Bryan. 1987. A diagnostic iceocean model. J. Phys. Oceanogr., 17(7), 987-1015. 